ECOLOGICAL HISTORY HAS PRESENT AND

" FUTURE ECOLOGICAL CONSEQUENCES CASE STUDIES FROM AUSTRALIA

\title{
David Lindenmayer
}

The Australian National University, Canberra, ACT, Australia 


\subsection{INTRODUCTION}

Ecology is often regarded as a case-study discipline (Shrader-Frechette \& McCoy 1993), and using case studies to develop general messages can be a critically important approach to inform resource-management practices and conservation actions (Fazey et al. 2006). Here, I present a personal perspective on the intersection between the ecological history of ecosystems and the management and conservation of those systems based on two case studies. The first study is drawn from a major research program that has continued for more than 27 years in the wet ash forests of the Central Highlands of Victoria, southeastern Australia (Lindenmayer 2009). The other is from Booderee National Park, Jervis Bay Territory (also in southeastern Australia), which has been running for a shorter period ( 9 years) (Lindenmayer et al. 2008b). Although the bulk of my comments focus on these case studies, there are some more general lessons that emerge that may have much broader applicability, and I touch briefly on them in the concluding section.

\subsection{CASE STUDY \# 1 - THE WET ASH FORESTS OF VICTORIA, SOUTHEASTERN AUSTRALIA}

The first case study is from the montane ash forests of the Central Highlands of Victoria. Mountain Ash (Bucalyptus regnans), Alpine Ash (Eucalyptus delegatensis), and Shining Gum (Bucalyptus nitens) dominate these forests. This region is close to Melbourne, Australia's second largest city, and it is notable because some of the forests it supports contain the tallest flowering plants on earth (with some trees exceeding $100 \mathrm{~m}$ in top height). The montane ash forests of the Central Highlands of Victoria also (1) are the source of most of the water for Melbourne, (2) provide habitat for a range of high-profile species such as the nationally endangered Leadbeater's Possum (Gymnobelidues leadbeateri), and (3) support a major timber and pulpwood industry, with almost all logging currently taking place by clear-cutting methods, although postfire salvage logging (which also involves clear-cutting) often occurs following high-severity conflagrations such as those which occurred in 1939. 1983 (Lindenmayer et al. 2008a), and most recently, in 2009.

Wildfire, logging, and biodiversity are intimately interlinked through ecological history and contem- porary management in montane ash forests, sometimes in unexpected and/or subtle ways. Many of these interrelationships have shaped montane ash forests in ways that have a major influence on current biotic assemblages, current forest management practices, and current wildlife management strategies. They also will have a significant effect on future fire and biodiversity management (Lindenmayer 2009). To understand these interrelationships, it is important first to provide some background on natural disturbance regimes in montane ash forests. The typical natural disturbance pathway in these forests is a highseverity, stand-replacing, or partial stand-replacing fire. Such fires kill most overstory eucalypt trees in montane ash forests. Unlike most Australian eucalypts, these trees rarely resprout from epicormic shoots. New cohorts of trees germinate en masse from seeds shed from the burned crowns of trees during a wildfire (Ashton 1975). These new young trees grow at truly phenomenal rates for the first 70 years - sometimes exceeding $1 \mathrm{~m}$ per year. However, they do not produce viable seed in the crown until they are 20 years of age, so if a second fire occurs before trees reach sexual maturity, stands of montane ash forest are eliminated.

Although wildfires can be stand-replacing or partial stand-replacing events in montane ash forests, they nevertheless leave significant biological legacies (sensu Franklin et al. 2000). Biological legacies are parts of the previous forest stand carried through the fire to the recovering forest. These can be large dead trees, living fire-scarred trees, large pieces of coarse woody debris, plants that have survived (even as seeds), rhizomes or rootstocks, and residual populations of animals. A suite of major studies over the past two decades has shown that biological legacies remaining from past fires play many key ecological roles in montane ash forests. For example, they speed post-disturbance recovery of many populations of plants and animals, and they have a strong influence on the successional trajectory of postfire forests. As an example, burnt forests with some living fire-scarred trees become multiaged stands; that is, forests with two or more age cohorts of overstory eucalypt trees. These kinds of stands are important because they support the highest species richness of arboreal marsupials, and they provide the high-quality habitat for individual species such as Leadbeater's Possum (Lindenmayer 2009). Multiaged stands are also where the highest known density for aboveground carbon biomass occurs any-

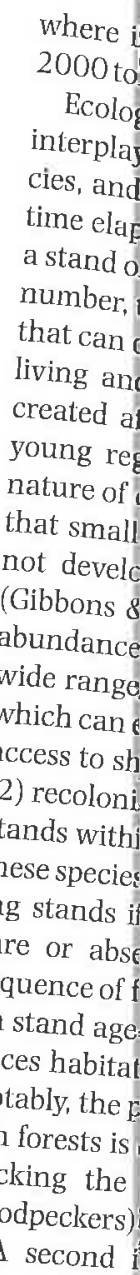

A second post-disturban salvage loggin and 1983 and wildfires. Thes of biological le example, the e: was reduced fro rently less than Similarly, past numbers of de? work suggests tt grams (especiall sive, it may take key structural hollows that are cavity-dependent (Lindenmayer \& 
where in the world, with measured values exceeding 2000 tonnes per hectare (Keith et al. 2009).

Ecological history can affect many aspects of the interplay between disturbance regimes, biological legacies, and biodiversity in montane ash forests. First, the time elapsed since a previous fire influences the age of a stand of montane ash forest. This, in turn, affects the number, type, and spatial pattern of biological legacies that can occur after a wildfire. For example, more large living and dead trees with hollows will persist or be created after a fire in an old-growth forest than if a young regrowth stand is burnt. This is because the nature of cavity ontogeny in montane ash trees means that small-diameter regrowth trees that are burnt do not develop hollows suitable for use by vertebrates (Gibbons \& Lindenmayer 2002). The occurrence and abundance of these biological legacies matters for a wide range of species of cavity-dependent vertebrates which can either (1) persist in burnt stands if they have access to shelter and den sites in trees with hollows or (2) recolonize burnt stands by occupying regenerating stands within 10-20 years after a fire. The majority of these species are absent from burnt but then regenerating stands if these kinds of cavity-tree resources are rare or absent (Lindenmayer 2009). Therefore, the sequence of fires in an area can have important impacts on stand age and stand structure, which in turn influences habitat suitability for a range of animal species. Notably, the process of cavity development in montane ash forests is slow and mediated by termites and fungi (lacking the accelerating effects of excavators like woodpeckers) (Lindenmayer 2009).

A second impact of ecological history relates to post-disturbance forest management. Post-disturbance salvage logging was widespread after wildfires in 1939 and 1983 and is now occurring after the recent 2009 wildfires. These operations remove extensive numbers of biological legacies that result from these fires. For example, the extent of multiaged montane ash forest was reduced from an estimated $30 \%$ of stands to currently less than 10\% (McCarthy \& Lindenmayer 1998). Similarly, past postfire salvage logging removes large numbers of dead trees with hollows. Indeed, recent work suggests that because past salvage logging programs (especially after the 1939 fires) were so pervasive, it may take 150-200 years for forests to recover key structural attributes such as large trees with hollows that are a critical habitat component for many cavity-dependent species in montane ash forests (Lindenmayer \& Ough 2006). That work also suggests that the colonization of salvage-logged forests by some species of cavity-dependent wildlife will be greatly accelerated by the retention of existing dead and living large trees with hollows in harvested areas.

A third impact of ecological history relates to traditional (green tree) clear-cut logging of montane ash forests. Clear-cutting leads to long-term stand structural simplification, converting old-growth stands to the start of the successional process, but lacking a large proportion of the biological legacies that characterize young regenerating forests after natural disturbance (Lindenmayer 2009). Field studies over the past 27 years indicate that the paucity of biological legacies in young clear-cut and regenerated stands makes them unsuitable as habitat for many species, particularly cavity-dependent ones.

There may be other effects of past logging history in montane ash forests. Recent work tentatively suggests that the history of clear-cut logging (including salvage logging) might have altered critical aspects of fire regimes such as increased fire severity (Lindenmayer et al. 2009). The mechanisms for this change remain unclear, but they may include:

1 Changing microclimates and fuel characteristics. These changes can lead to increased drying of understory vegetation and the forest floor through reductions in water-holding mosses and the humus layer. This can alter the amount, type, and moisture content of fuels. 2 Altering the structure and plant species composition of stands. Such changes not only alter microclimatic conditions as described above, but also can change stocking densities and patterns of trees, inter-crown spacing of trees, and other forest attributes such as plantspecies composition. This, in turn, can influence fire behavior. For example, clear-cutting leads to the development of dense stands of regrowth saplings that can create more available fuel than if the forest is not clear-cut.

3 Altering patterns of landscape cover. Logging operations change natural patterns of spatial juxtaposition of different kinds of forest stands, resulting in homogenization of the age-class structure. This, in turn, may change the way that fire spreads through landscapes. For example, some areas traditionally characterized by an absence of fire may become more susceptible to fires that spread from adjacent, more flammable, logged areas. Notably, places such as closed-water catchments where logging operations have never occurred contain stands of old-growth forest with evidence of past fires, but those disturbances have been 
repeated, low-severity fires that have not been standreplacing and instead have produced multiaged forests (Lindenmayer et al. 2000). Importantly, a broader view of natural-disturbance history regimes in montane ash forests suggests the existence of a range of disturbance pathways beyond the single simple one "of complete stand-replacing wildfires.

Interrelationships between clear-cutting and wildfire may create the potential for negative feedbacks between human disturbance, natural disturbance, and declining stand age across montane ash landscapes. That is, young regrowth forests resulting from clearcutting have a higher risk of burning and then being salvage logged. They may then be "fire-trapped" (Fig. 19.1), making it difficult for them to avoid being reburnt and precluding them from reaching an oldgrowth stage (typically 200+ years). An additional major risk is recurrent fire at intervals of less than 20 years. In such cases, montane ash forest would be lost entirely and replaced by other vegetation types, such as stands dominated by understorey Acacia spp. trees (Lindenmayer 2009). This would have substantial consequences for plant and animal species associated with montane ash forest.

In summary, the history of clear-cutting and postfire salvage logging has influenced the spatial distribution and abundance of key biological legacies such as large trees with hollows throughout montane ash forests (Lindenmayer et al. 1991). It also has affected the composition of stand age classes in montane ash forest landscapes. This, in turn, has influenced the spatial distribution and abundance of a suite of cavity-tree associated animals in these forests (Lindenmayer et al. 1994). Hence, the present distribution patterns of large tree and animal species are a reflection of ecological history, particularly past natural and human disturbance events, combinations of the two (i.e. salvage logging), and the cumulative effects of both (i.e. logging-induced changes in fire regimes).

\section{Ecological history, forest management, fire management, and biodiversity conservation}

The findings outlined above have several important implications for forest management, postfire management practices, and biodiversity conservation in montane ash forests, and likely other forest types as well. First, existing stands of old growth and multiaged forest have unique values that would be lost through either clear-cut logging or salvage logging. This is because they are places where (1) significant numbers

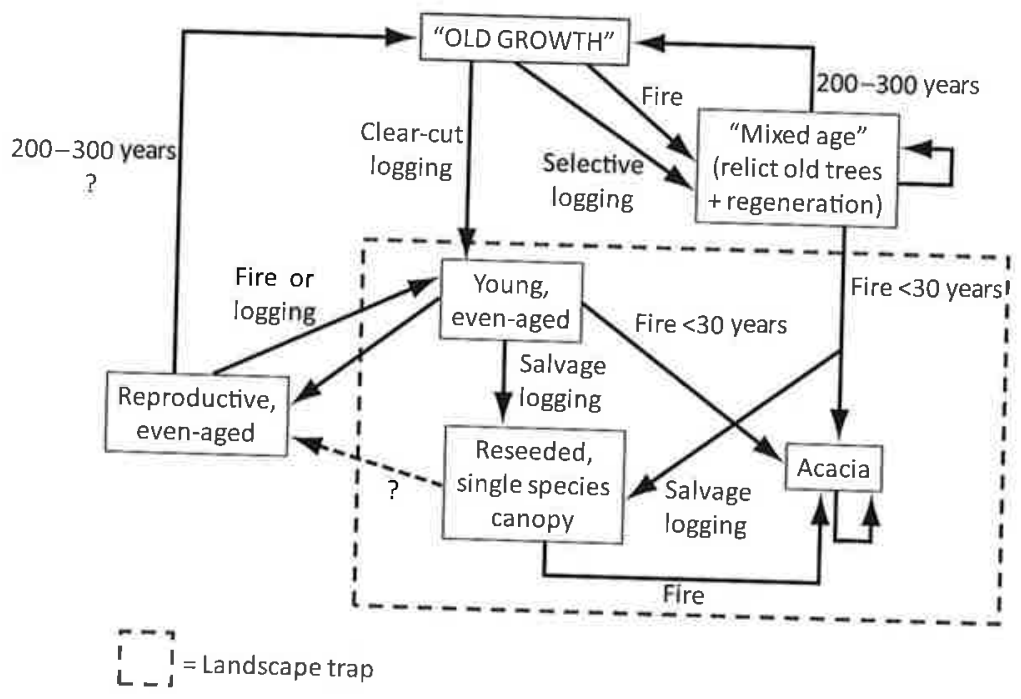

Fig. 19.1 Conceptual model of the interplay between forest age, wildfire, clear-cut logging, and salvage logging in montane ash forests. The hatched line encompasses a landscape fire trap in which there are negative feedbacks between natural and . 
of biological legacies occur - both in the absence of fire and after major wildfires; (2) a range of species of conservation significance is most likely to occur; and (3) ecological recovery is likely to be fastest if a wildfire occurs. Moreover, remaining old-growth stands will assume increasing importance as more of the remaining old forest is logged, burnt, or both. The ecological values of old-growth stands are well recognized by government authorities responsible for the management of montane ash forests, which are now exempt from harvesting, including postfire salvage logging. As a consequence, a zoning system has been adopted in forests broadly designated for wood production. These zones delineate areas that are and are not available for timber and pulpwood production. For example, there are Special Protection Zones where the primary management action is the conservation of species such as Leadbeater's Possum (Macfarlane et al. 1998). In essence, this means that ecological history has underpinned the location of different parts of the forest where different kinds of management actions have priority. A second important implication of the ecological history of fire, salvage logging, and clear-cutting is the relative paucity of large trees with hollows across substantial areas of regrowth montane ash forest. The problems for biodiversity conservation created by such kinds of stand simplification are now well recognized. In response, alternative silvicultural systems to traditional clear-cutting practices are being tested in an attempt to better retain and/or create new cohorts of large trees in logged areas, as well as to develop more stands with multiple-age cohorts of trees. These new systems are modeled on the Variable Retention Harvest System developed in northwestern North America (Franklin et al. 1997) and are based on retaining islands of protected unlogged forest within harvest units. Importantly, studies of natural-disturbance regimes and landscape history indicate that flat and undulating areas with southerly aspects are those where multiaged stands are most likely to occur naturally (Mackey et al. 2002), and this has been used to guide where alternative island-retention logging systems would be best applied (Lindenmayer 2009).

A third important implication of the intersection of ecological history of fire, salvage logging, and clearcutting is how it can change people's perceptions of what is "natural" in many ecosystems. This change in perception is akin to the shifting baseline concept widely used in marine ecosystems (Baum \& Myers 2004) but less well known in forest environments. In
Victorian montane ash forests, forest managers failed to recognize that multiage stands were once far more widespread because evidence of them had largely been lost from wood-production areas. This stemmed from recurrent logging, high-intensity wildfires, and postfire salvage logging leading to widespread even-aged regrowth stands. In contrast, work in unlogged water catchments has highlighted that the prevalence of multiaged stands is much greater than previously recognized (McCarthy \& Lindenmayer 1998).

\subsection{CASE STUDY \# 2 - BOODEREE NATIONAL PARK, JERVIS BAY TERRITORY, SOUTHEASTERN AUSTRALIA}

My second (and shorter) case study is also from southeastern Australia and also has key underlying themes of fire, vegetation cover, and biodiversity conservation. It is based on 6600-ha Booderee National Park, in the Jervis Bay Territory. The area is notable for its extraordinary diversity of vegetation types in a relatively small area - ranging from warm temperate rainforest to open woodland and coastal heathland. It also supports highly diverse floral and faunal assemblages, including a suite of endangered species such as the Eastern Bristlebird (Dasyornis brachypterus) and the Barkley's Grevillea (Grevillea barkleyana), of which the park supports some of the most significant remaining populations.

Fire is a key ecological process in Booderee National Park, and the area has been subject to many past wildfires and extensive prescribed burning (Baker 2000). Indeed, Booderee National Park has some of the bestkept fire-history records of any location in southeastern Australia. Two key areas of work have particular relevance to the theme of ecological history and contemporary management and conservation. The first was a detailed longitudinal investigation of postfire recovery of various vertebrate groups following a major conflagration in 2003, in which approximately half of Booderee National Park was burnt. The second was an empirical study of relationships between fire history and site-level vertebrate species richness (see Lindenmayer et al. 2008b for both studies).

A key (and somewhat surprising) finding of our first study quantifying postfire ecological recovery was that, after the fire in 2003, the majority of individual bird species and the bird assemblage as a whole in most vegetation types recovered within 2 years to what it 
had been prior to the fire. There also were few, if any, major differences in populations of individual bird species and the bird assemblage between areas that had been burnt in 2003 and those that had not. Post* fire conditions, particularly high levels of rainfall, appear to have promoted vegetation growth and structural regeneration, aiding bird species recovery in most vegetation types. In addition, the presence of biological legacies remaining after a fire either facilitated the persistence of a given species on a site or promoted the speed or recovery of some species to pre-disturbance levels. For example, the amount of unburned vegetation within a burnt site and in the area immediately surrounding a site was a significant explanatory variable in logistic regression models for observed species richness in 2004 (immediately following the 2003 wildfire) and also in statistical models developed for a number of individual species.

In the second study, historical data on fire were linked with detailed empirical data gathered since 2002 on the occurrence and abundance of birds, reptiles, mammals, and amphibians at 110 permanent field sites. An example of the many results derived from this work was that although most of the bird assemblage recovered quickly following the 2003 fire, longer term fire history was found to have had a highly significant effect on observed bird species richness. Richness was reduced by $9.1 \%$ per fire over the past 35 years, irrespective of the vegetation type that was examined; it was lowest on sites burnt five times since 1974 .

\section{Ecological history, fire management, and biodiversity conservation}

The results outlined above have some important implications for fire-management practices and their intersection with biodiversity conservation in Booderee National Park. First, it is clear that recovery after a single fire did not reflect the long-term effects of multiple fires on overall bird species richness at a site. Hence, there is a need for the careful application of subsequent planned fires such as hazard reduction or prescribed burns to any given site. Because of the relationships between increasing numbers of fires and reduced observed species richness at a site, fire history should guide decisions about where to apply such planned burns. For example, places where there is a history of many past fires should be exempt from additional nearand medium-term planned fires such as those used for prescribed burning. In addition, there is considerable value in identifying places that have been fire-free for a prolonged period, quantifying the characteristics of the vegetation structure and plant species composition in those areas, and then attempting to maintain those features as part of management interventions in other parts of Booderee National Park.

A second important implication arising from the empirical results of work at Booderee National Park is that biological legacies matter - an outcome reinforcing one of the key themes in the first case study. Biological legacies either facilitate the persistence of species on burnt sites or speed their postfire recovery. Hence, the presence of some species on sites will be influenced, in part, by the legacies that remain on a site following a previous disturbance (Franklin et al. 2000). Informed fire-management practices need to ensure that the ecological integrity of biological legacies is not impaired. For example, in some jurisdictions, firesuppression activities involve back burning that attempts to halt a fire front or "black-out" unburnt areas not "consumed" by a fire. This may lead to a loss of key biological legacies like unburnt patches or patches initially subject to low-severity fire (Backer et al. 2004). Data from Booderee National Park on the importance of the amount of unburnt vegetation within and surrounding a site suggest that these practices have the potential to negatively influence the postfire response of some elements of the biota. The lesson from ecological history in this case is that contemporary management practices should avoid practices like black-out burning wherever possible because of their effects on biodiversity, particularly postfire ecological recovery. Such practices can reduce landscape heterogeneity (such as the mosaic of burned and unburned patches), and this also can have negative impacts on biodiversity (Lindenmayer et al. 2008b) as well as likely postfire ecological recovery.

Issues associated with the integration of fire management and biodiversity conservation are critical ones for Booderee National Park and many other similar places, both in southeastern Australia and elsewhere in the world. This is because an array of studies has predicted that fire size, fire frequency, and/or fire severity will increase in the near future in many parts of the world as a consequence of climate change (Cary 2002; Lenihan et al. 2003). The potential for increasing fire frequency and severity has led to widespread calls for more prescribed burning and more intensive fire-suppression efforts once a major fire event has 
started. The impacts of these actions on biodiversity conservation need to be carefully considered, particularly in the context of fire history and the biological legacies that result from natural, spatially patchy fires but are missing from the uniformly burnt areas that can result from fire-suppression activities like blackout burning.

\subsection{CONCLUDING COMMENTS}

It is clear from work in many parts of the world that ecological history can have a significant effect on current ecological conditions, contemporary management, and on future management. The two case studies I have described illustrate this key point. However, there are other important lessons from these case studies. In particular, some historical effects can last longer and be more pervasive than many people previously believed (cf Jones \& Schmitz 2009). The loss of large cavity trees in montane ash forests and the prolonged period for recruitment (spanning one to two centuries) is a classic example. A second lesson relates to debates about the effects of climate change. Both case studies in this chapter indicate that any effects of future climate change would not take place on a blank canvas. Rather, the impacts of climate change will be influenced by the ecological history of past disturbances as well as past and current management actions. For example, the regeneration niches of tree species in montane ash forests are predicted to be severely challenged by potential future changes in temperature and rainfall; hence, there may be interrelationships with the amount of forest regenerating after logging, after fire, or both. Indeed, climate change is also likely to drive substantial changes in fire regimes in southeastern Australia (Cary 2002; Steffen et al. 2009). It is therefore critical to identify and then manage the factors that may exacerbate problems associated with the alterations in fire regimes driven by climate change. If preexisting factors such as logging change fire proneness, then interactions between logging and climate change could lead to cumulative negative impacts, including those on biodiversity. Conversely, recent work in Amazonia suggests that some kinds of forest may have an inherent "resilience" to climate change through maintaining mesic microclimate conditions if they remain undisturbed by other factors like logging (Mahli et al. 2009). This finding suggests that careful consideration must be given to past disturbance regimes and present management practices to better prepare natural environments for future changes in climate, with the overarching aim of reducing risks of potential interaction effects.

\section{ACKNOWLEDGMENTS}

The content of this chapter has been informed by numerous collaborative partnerships with many colleagues over the past 25 years. In particular, I thank Ross Cunningham and Jeff Wood for outstanding statistical insights that have led to some of the most important discoveries in the Victorian forests and at Jervis Bay.

\section{REFERENCES}

Ashton, D.H. (1975). The root and shoot development of Eucaluptus regnans F. Muell. Australian Journal of Botany, 23, $867-887$

Backer, D.M., Jensen, S.E., \& McPherson, G.R. (2004). Impacts of fire suppression activities on natural communities. Conservation Biology, 18, 937-944.

Baker, J.R. (2000), The Eastern Bristlebird: cover-dependent and fire-sensitive. Emu, 100, 286-298.

Baum, J.K. \& Myers, R.A. (2004), Shifting baselines and the decline of pelagic sharks in the Gulf of Mexico. Ecology Letters, 7, 135-145.

Cary, G. (2002). Importance of a changing climate for fire regimes in Australia. In Flammable Australia (ed. R.A. Bradstock, J.E. Williams, and A.M. Gill), pp. 26-48. Cambridge University Press, Melbourne, Australia.

Fazey, I., Fazey, J.A., Salisbury, J.G., \& Lindenmayer, D.B. (2006). The nature and role of experiential knowledge for environmental conservation. Environmental Conservation, 33, $1-10$.

Franklin, J.E., Berg, D.E., Thornburgh, D.A., \& Tappeiner, J.C. (1997). Alternative silvicultural approaches to timber harvest: variable retention harvest systems. In Creating $A$ Forestry for the 21st Century (ed. K.A. Kohm and J.F. Franklin), pp. 111-139. Island Press, Covelo, CA, USA.

Franklin, J.F., Lindenmayer, D.B., MacMahon, J.A., et al. (2000). Threads of continuity: ecosystem disturbances, biological legacies and ecosystem recovery. Conservation Biology in Practice, 1, 8-16.

Gibbons, P. \& Lindenmayer, D.B. (2002). Tree Hollows and Wildlife Conservation in Australia. CSIRO Publishing, Melbourne, Australia.

Jones, H.P. \& Schmitz, O.J. (2009). Rapid recovery of damaged ecosystems. PLoS ONE, 4(5), e5653. 
Keith, H., Mackey, B.G., \& Lindenmayer, D.B. (2009). Reevaluation of forest biomass carbon stocks and lessons from the world's most carbon-dense forests. Proceedings of the National Academy of Sciences of the United States of America, 106, 11635-11640.

Lénihan, J.M., Drapek, R., Bachelet, D., \& Neilson, R.P. (2003). Climate change effect on vegetation distribution, carbon, and fire in California. Ecological Applications, 13, 16671681 .

Lindenmayer, D.B. (2009). Forest Pattern and Ecological Process: A Synthesis of 25 Years of Research. CSIRO Publishing, Melbourne, Australia.

Lindenmayer, D.B. \& Ough, K. (2006). Salvage logging in the montane ash eucalypt forests of the Central Highlands of Victoria and its potential impacts on biodiversity. Conservation Biology, 20, 1005-1015.

Lindenmayer, D.B., Cunningham, R.B., Nix, H.A., Tanton, M.T., \& Smith, A.P. (1991). Predicting the abundance of hollow-bearing trees in montane ash forests of southeastern Australia. Australian Journal of Ecology, 16, 9198.

Lindenmayer, D.B., Cunningham, R.B., \& Donnelly, C.F (1994). The conservation of arboreal marsupials in the montane ash forests of the Central Highlands of Victoria, south-eastern Australia: VI. T'he performance of statistical models of the nest tree and habitat requirements of arboreal marsupials applied to new survey data. Biological Conservation, 70, 143-147.

Lindenmayer, D.B., Cunningham, R.B., Donnelly, C.F., \& Franklin, J.F. (2000). Structural features of old growth Australian montane ash forests. Forest Ecology and Management,
134, 189-204.
Lindenmayer, D.B., Burton, P.J., \& Franklin, J.F. (2008a). Salvage Logging and Its Ecological Consequences. Island Press. Washington, DC, USA.

Lindenmayer, D.B., Wood, J.T., Cunningham, R.B., et al. (2008b). Testing hypotheses associated with bird responses to wildfire. Ecological Applications, 18, 1967-1983.

lindenmayer, D.B., Hunter, M.L., Burton, P.J., \& Gibbons, P (2009). Effects of logging on fire regimes in moist forests. Conservation Letters, 2, 271-277.

Macfarlane, M.A., Sinith, J., \& Lowe, K. (1998). Leadbeater's Possum (Gymnobelideus leadbeateri) recovery plan, 19982002. Department of Natural Resources and Environment, Government of Victoria, Melbourne, Australia.

Mackey, B., Lindenmayer, D.B., Gill, A.M., McCarthy, M.A., \& Lindesay, J.A. (eds.). (2002). Wildlife, Fire and Future Clinate; A Forest Ecosystem Analysis. CSIRO Publishing, Melbourne,
Australia.

Mabli, Y., Aragao, L.E., Galbraith, D., et al. (2009). Exploring the likelihood and mechanism of a climate-change-induced dieback of the Amazon rainforest. Proceedings of the National Academy of Sciences of the United States of America, 106, 20610-20615.

McCarthy, M.A. \& Lindenmayer, D.B. (1998). Multi-aged Mountain Ash forest, wildlife conservation and timber harvesting. Forest Ecology and Management, 104, 43-56.

Shrader-Frechette, K.S. \& McCoy, E.D. (1993). Method in Ecology: Strategies for Conservation. Cambridge University
Press, Cambridge, UK.

Steffen, W., Burbidgc, A., Hughes, L., et al. (2009). Australia's Biodiversity and Climate Change. CSIRO Publishing, Melbourne, Australia. 